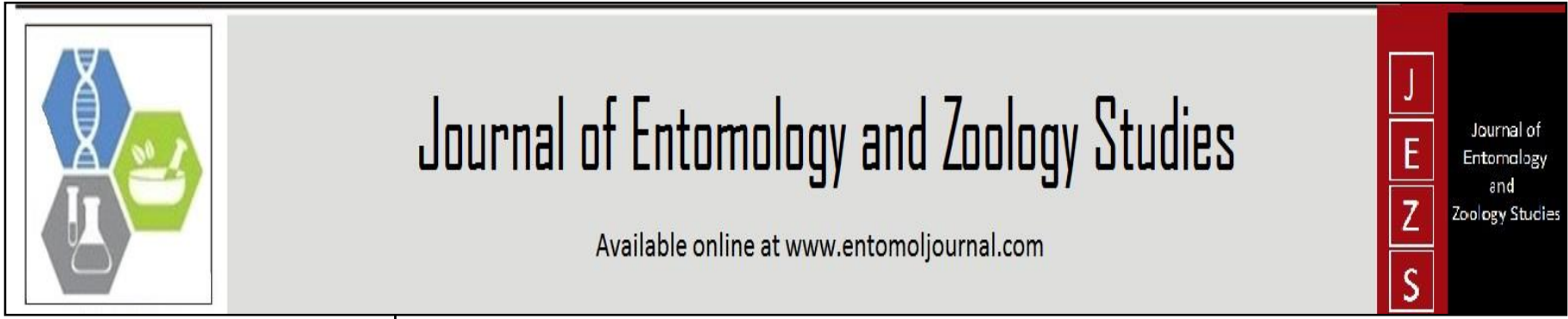

E-ISSN: 2320-7078 P-ISSN: 2349-6800 JEZS 2018; 6(4): 1569-1572 (C) 2018 JEZS

Received: 16-05-2018

Accepted: 17-06-2018

Mark Cooper

KwaZulu-Natal Museum, 237 Jabu Ndlovu Street,

Pietermaritzburg, KwaZuluNatal, South Africa
Correspondence Mark Cooper

KwaZulu-Natal Museum, 237 Jabu Ndlovu Street,

Pietermaritzburg, KwaZuluNatal, South Africa

\title{
Centrobolus anulatus (Attems, 1934) reversed sexual size dimorphism
}

\section{Mark Cooper}

\section{Abstract}

The present research aimed to study relative sexual size dimorphism of Centrobolus anulatus compared to congenerics. Millipedes illustrated reversed sexual size dimorphism (SSD) as females were larger than males and broke the rule as this dimorphism increased with body size. SSD was calculated in 18 species of the genus Centrobolus and illustrated as a regression. The approximate relative position of $C$. anulatus was shown from measurements taken in South Africa (2018). The average size of $C$. anulatus was $74.23529412 \times 5.685882 \mathrm{~mm}(\mathrm{n}=17)$; males measured $69.2 \times 5.264 \mathrm{~mm}(\mathrm{n}=5)$ and females were 76.3 X $5.861667 \mathrm{~mm}(\mathrm{n}=12)$. Log volume measurements were $\left(\right.$ females $/ \mathrm{x}=3.31359939 \mathrm{~mm}^{3} ;$ males $/ \mathrm{y}=$ $3.2377543 \mathrm{~mm}^{3}$ ). The difference between the correlation coefficients for the species and the genus were not highly significant $\left(\mathrm{r}_{\mathrm{a}}=0.86207, \mathrm{r}_{\mathrm{b}}=0.85 ; \mathrm{n}_{\mathrm{a}}=17, \mathrm{n}_{\mathrm{b}}=18 ; \mathrm{Z}=0.12 ; \mathrm{P}\right.$ (one-tailed) $=0.4522$, $\mathrm{P}$ (twotailed $)=0.9045)$. The mean volume ratio for $C$. anulatus was 1.02342521 which differed from 1 $(\mathrm{t}=3.59722 ; p$-value $=000747 ; p<.01 ; \mathrm{n}=17)$. Evidence suggests sexual bimaturism as proximate cause and competition as ultimate cause for SSD in Centrobolus.

Keywords: Centrobolus anulatus, dimorphism, millipede, SSD, size

\section{Introduction}

Sexual size dimorphism is prevalent in arthropods and females are usually larger than males. Behavioural patterns such as provisioning versus non- provisioning relate to SSD. Millipedes illustrate reversed sexual size dimorphism (SSD) and females are larger than males [23, 27, 29, 34]. Diplopoda are underrepresented in allometric analyses of sexual size dimorphism (SSD), although sexual size differences are known in body mass, length, width and leg dimensions of over half the taxa studied ${ }^{[5-9,23,26-27]}$. Size differences correlate with factors such as color, sexes, species, urbanisation and water relations ${ }^{[25-26,31,34]}$. Diplopoda resemble the majority of invertebrates where SSD is reversed ${ }^{[12-14,20-22]}$. SSD has consequences for outcomes of sexual encounters in diplopod mating [1, 4-9, 11, 15, 25-27, 29, 34]. The allometry of SSD involves the detection of a relationship between body size and SSD and is known by Rensch's rule [32-33]. Rensch's rule may be explained by sexual selection and fecundity selection ${ }^{[24,30]}$. The macroevolutionary pattern is unresolved in Diplopoda. Here, Rensch's rule was tested in predicting SSD was not negatively correlated with diplopod body size in African forest and savanna taxa. SSD in the forest genus Centrobolus was investigated. SSD in forest millipedes have successfully been understood as volumetric measurements using Centrobolus to test Rensch's rule. The general trend of SSD has been calculated for Centrobolus and bimaturism shown ${ }^{[7]}$. The present study was aimed to illustrate the trend of SSD for the genus Centrobolus and estimate the position of $C$. anulatus relative to 18 congenerics in order to determine whether species follow the trend of Rensch's rule.

\section{Materials and methods}

Two factors were measured from Centrobolus anulatus: (1) body length (mm) placing a piece of string along the body length of individuals collected in South Africa (Table 1) and measuring the string alongside a rule (calibrated in $\mathrm{mm}$ ), and (2) width ( $\mathrm{mm}$ ) with Vernier calipers. C. anulatus (Attems) were collected at the localities in Table 1 from KwaZulu-Natal, South Africa. Any measurement error associated with the transfer of measurement between string and rule would be the same for both sexes. Millipede SSD was also calculated in the genus Centrobolus ${ }^{[2-3,5-9]}$. A regression of male volume on female volume was used to show the position of 18 species and the size of $C$. anulatus was taken as a volumetric measurement and inserted into a Microsoft (MS) Excel spreadsheet and converted using the log 
(mathematical) equation. The chart for SSD in 18 species was captured, copied and exported using the snapshot function in the programme Soda Portable Document File (PDF) 8. It was pasted in a MS Word file.

\subsection{Statistical Analysis}

The basic descriptive figures were statistically compared using Statistica. Body length: width ratios were inputted into the formula for a cylinder. The mean values of length and width was obtained for 17 individuals of $C$. anulatus. Size was perceived as body volume and calculated based on the formula for a cylinder $\left(h \cdot \pi \cdot r^{2}\right)$ where $h$ is body length and $r$ half of the width. SSD was estimated as the mean female volume divided by mean male volume and converted into a SSD index. Allometry for SSD was based on an allometric model where male size $=\alpha$ (female) ${ }^{\beta}$. A Spearman's Rho calculation was made in order to test the correlation between the male and female data measurements at http://www.socscistatistics.com/tests/spearman/Default3.aspx. Correlation coefficients were compared at http://vassarstats.net/rdiff.html. SSD was compared against to 1 using a two-tailed t-test at http://www.socscistatistics.com/tests/studentttest/Default2.asp $\mathrm{x}$.

\section{Results}

The quantitative resolution of Rensch's rule for 18 species of Centrobolus together with the relative estimated position of $C$. anulatus is shown in Fig. 2. The average size of $C$. anulatus was 74.23529412 X $5.685882 \mathrm{~mm}(\mathrm{n}=17)$; males measured $69.2 \times 5.264 \mathrm{~mm}(\mathrm{n}=5)$ and females were $76.3 \mathrm{X}$ $5.861667 \mathrm{~mm}(\mathrm{n}=12)$. Log volume measurements were (females $/ \mathrm{x}=3.31359939 \mathrm{~mm}^{3} ;$ males $/ \mathrm{y}=3.2377543 \mathrm{~mm}^{3}$ ) (Figure 3). The mean volume ratio for $C$. anulatus was 1.02342521. SSD was visible with the naked eye. There was a correlation between the $\log$ values for male and female volumes. The value of $\mathrm{R}$ was 0.86207 and the two-tailed value of $\mathrm{P}$ is 0.00134 . By normal standards, the association between the two variables would be considered statistically significant. The difference between the correlation coefficients for the species and the genus was not highly significant $\left(\mathrm{r}_{\mathrm{a}}=0.86207, \mathrm{r}_{\mathrm{b}}=0.85 ; \mathrm{n}_{\mathrm{a}}=17, \mathrm{n}_{\mathrm{b}}=18 ; \mathrm{Z}=0.12\right.$; $\mathrm{P}$ (one-tailed) $=0.4522, \mathrm{P}=0.9045)$ (Fig. 1). SSD was significantly different from $1(\mathrm{t}=3.59722 ; p$-value $=000747 ; p$ $<.01 ; \mathrm{n}=17)$.

Table 1: Centrobolus annulatus morphological measurements.

\begin{tabular}{|c|c|c|c|c|}
\hline $\begin{array}{c}\text { KZN Museum } \\
\text { Accession number }\end{array}$ & $\begin{array}{c}\text { Sex } \\
(\mathbf{M} / \mathbf{F})\end{array}$ & $\begin{array}{c}\text { Length } \\
(\mathrm{mm}) \text { _string }\end{array}$ & $\begin{array}{c}\text { Width } \\
\text { (mm) }\end{array}$ & Locality \\
\hline NMSA25977 & $\mathrm{F}$ & 73 & 5,8 & KZN, Mabengu forest, coast lowlands forest, on scrambler in forest \\
\hline NMSA25994 & $\mathrm{F}$ & 65 & 5,6 & KZN, Vernon Crookes Nature Reserve \\
\hline NMSA25974 & $\mathrm{F}$ & 84 & 6,8 & KZN, Mabengu forest, coastal lowlands forest, on forest floor with thick underground of ferns \\
\hline NMSA25995 & $\mathrm{F}$ & 82 & 5,52 & KZN, Vernon Crookes Nature Reserve, forest hillside, on pole at edge of camp \\
\hline NMSA25910 & $\mathrm{F}$ & 71 & 6,22 & KZN, Blythedale Beach, Farm Blyth Dale 1380 \\
\hline NMSA15551a & M & 65 & 5,08 & KZN, Hawaan forest \\
\hline NMSA15551b & $\mathrm{F}$ & 85 & 5,9 & KZN, Hawaan forest \\
\hline NMSA25930 & $\mathrm{F}$ & 74 & 5,7 & KZN, Bluff Nature Reserve \\
\hline NMSA16491 & $\mathrm{F}$ & 70 & 5,3 & KZN, Kranzkloof Nature Reserve \\
\hline NMSA25911a & M & 78 & 5,8 & KZN, Blythedale Beach, Farm Blyth Dale 1380 \\
\hline NMSA25911b & $\mathrm{F}$ & 88 & 7,36 & KZN, Blythedale Beach, Farm Blyth Dale 1381 \\
\hline NMSA25975 & $\mathrm{M}$ & 68 & 5,7 & KZN, Mabengu forest, coastal lowlands forest, on felled coastal cabbage tree \\
\hline NMSA15541a & $\mathrm{F}$ & 68 & 5,12 & KZN, Durban Bluff, off Berea rd. \\
\hline NMSA15541b & M & 68 & 4,82 & KZN, Durban Bluff, off Berea rd. \\
\hline NMSA15541c & $\mathrm{M}$ & 67 & 4,92 & KZN, Durban Bluff, off Berea rd. \\
\hline NMSA15541d & $\mathrm{F}$ & 72 & 5,00 & KZN, Durban Bluff, off Berea rd. \\
\hline NMSA15571 & $\mathrm{F}$ & 84 & 6,02 & KZN, Harold Johnson Nature Reserve \\
\hline
\end{tabular}

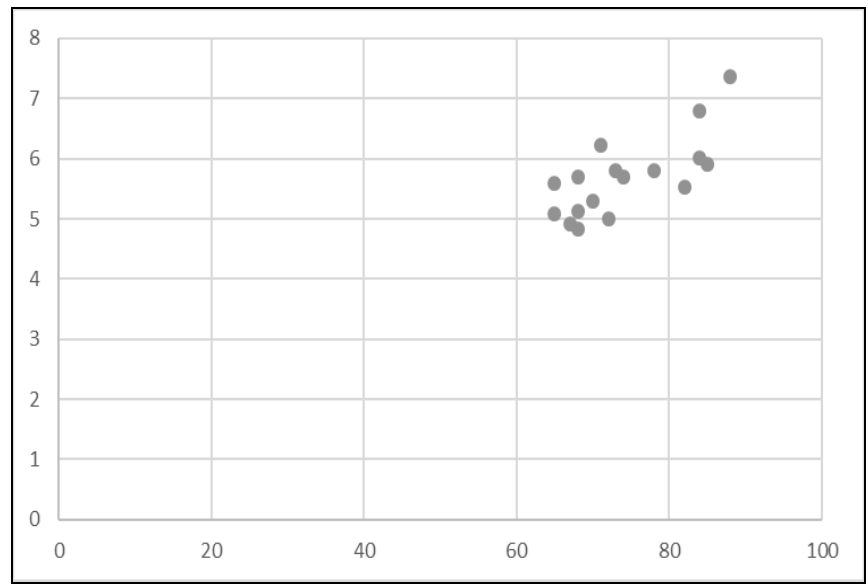

Fig 1: Quantitative resolution of sexual size dimorphism for 17 specimens of the millipede Centrobolus anulatus. Allometry for sexual size dimorphism (SSD) is based on the allometric model ${ }^{[28]}$, male size $=\alpha(\text { female size })^{\beta}$; correlation coefficient, $r=0.86207(\mathrm{P}=$ $0.00134)$

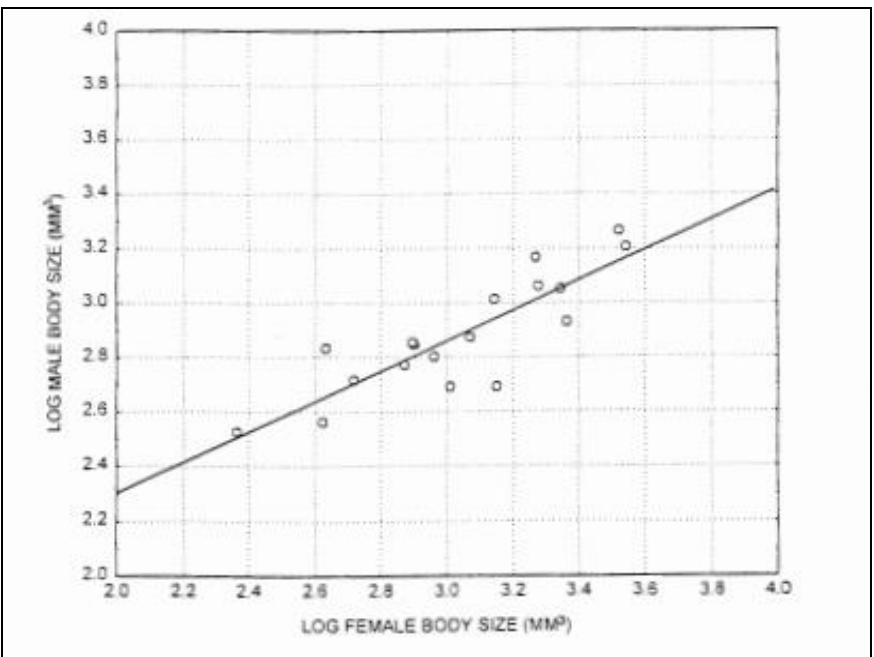

Fig 2: Quantitative resolution of sexual size dimorphism for 18 species of millipedes of the genus Centrobolus. Allometry for sexual size dimorphism (SSD) is based on the allometric model ${ }^{[28]}$, male size $=\alpha(\text { female size })^{\beta}$; correlation coefficient, $r=0.85$. 


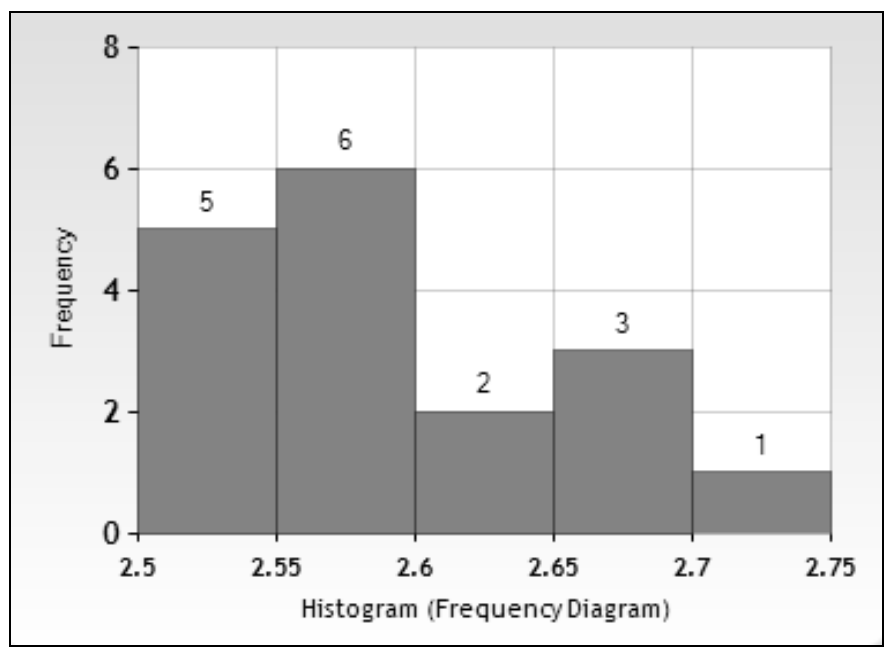

Fig 3: Distribution frequency histogram for male and female volumes of Centrobolus anulatus.

\section{Discussion}

Previous studies on SSD in invertebrates and these results consistently give a positive correlation and break the rule ${ }^{[5,10,}$ 12-19, 36]. Figure 1 shows the finding for Centrobolus anulatus where the regression of log male volume on log female volume was highly significant with a positive slope of 0.86207; showing females get larger than males with an increase in body size ${ }^{[2-3,7-8]}$. SSD was significantly different from 1 in this species. Mean volume ratio of 1.02342521 for C. anulatus was a trend for the genus in Fig. 2. As a proximate cause for SSD in millipedes the evidence suggests the Sexual Bimaturism hypothesis ${ }^{[7]}$. As ultimate cause for SSD this together with ecological evidence suggests intersexual competition ${ }^{[2]}$. Evidence for sexual selection on dimorphism based on the relative size dimorphism in $C$. anulatus implies size would be important in determining the outcome of mating [11, 15, 34-35]. The mechanism based on a conflict of interests is known in $C$. inscriptus ${ }^{[8]}$. In the millipede Doratogonus uncinatus female choice for mating partners is "size selective" [35]. The cross-mating experiments in Centrobolus suggest a combination of size assortative mating without a size based preference operates ${ }^{[2]}$. Studies of diplopod sexual dimorphism may include more taxa and make use of the length and width measurements to calculate volumes using the geometric morphometric approach shown here for finding causal relationships of dimorphism.

\section{Conclusion}

Precise measurements for $C$. anulatus show sexual size dimorphism with small males and larger females.

\section{Acknowledgement}

Staff of KwaZulu-Natal (KZN) Museum assisted in collection of measurements.

\section{References}

1. Akkari N, Enghoff H. Copulatory-copulatory male succession and male slenderness in Ommatoiulus sempervirilis $\mathrm{n}$. sp., a new insular millipede from Tunisia (Diplopoda: Julida: Julidae). Journal of Zoological Systematics and Evolutionary Research. 2011; 49(4):285291.

2. Cooper MI. Sex ratios, mating frequencies and relative abundance of sympatric millipedes in the genus Centrobolus Cook. Arthropods. 2014a; 3(4):174-176.
3. Cooper MI. Sexual size dimorphism and corroboration of Rensch's rule in Chersastus millipedes (Diplopoda: Trigoniulidae). Journal of Entomology and Zoology Studies. 2014b; 2(6):264-266.

4. Cooper M. Post-insemination associations between males and females in Diplopoda. Journal of Entomology and Zoology Studies. 2016; 4(2):283-285.

5. Cooper MI. Fire millipedes obey the female sooner norm in cross mating Centrobolus Cook. Journal of Entomology and Zoology Studies. 2016a; 4(1):173-174.

6. Cooper MI. Heavier-shorter-wider females in the millipede Centrobolus inscriptus (Attems). Journal of Entomology and Zoology Studies. 2016b; 4(2):509-510.

7. Cooper MI. Sexual bimaturism in the millipede Centrobolus inscriptus (Attems). Journal of Entomology and Zoology Studies. 2016c; 4(3):86-87.

8. Cooper MI. Sexual conflict over the duration of copulation in Centrobolus inscriptus (Attems). Journal of Entomology and Zoology Studies. 2016e; 4(6):852-854.

9. Cooper MI. The relative sexual size dimorphism of Centrobolus inscriptus compared to 18 congenerics. Journal of Entomology and Zoology Studies. 2016d; 4(6):504-505.

10. Cooper M. Re-assessment of rensch's rule in Centrobolus. Journal of Entomology and Zoology Studies. 2017; 5(6):2408-2410.

11. Cooper MI. The effect of female body width on copulation duration in Centrobolus inscriptus (Attems). Journal of Entomology and Zoology Studies. 2017a; $5(1): 732-733$.

12. Cooper MI. Relative sexual size dimorphism in Centrobolus digrammus (Pocock) compared to 18 congenerics. Journal of Entomology and Zoology Studies 2017b; 5(2):1558-1560.

13. Cooper MI. Relative sexual size dimorphism in Centrobolus fulgidus (Lawrence) compared to 18 congenerics. Journal of Entomology and Zoology Studies. 2017c; 5(3):77-79.

14. Cooper MI. Relative sexual size dimorphism Centrobolus ruber (Attems) compared to 18 congenerics. Journal of Entomology and Zoology Studies. 2017d; 5(3):180-182.

15. Cooper MI. Size matters in myriapod copulation. Journal of Entomology and Zoology Studies. 2017e; 5(2):207208.

16. Cooper M. Trigoniulid size dimorphism breaks Rensch. Journal of Entomology and Zoology Studies. 2018d; 6(3):1232-1234.

17. Cooper M. A review of studies on the fire millipede genus Centrobolus (Diplopoda: Trigoniulidae). Journal of Entomology and Zoology Studies. 2018; 6(4):126-129.

18. Cooper M. Centrobolus size dimorphism breaks Rensch's rule. Arthropods. 2018;

19. Cooper MI. Volumes of Centrobolus albitarsus (Lawrence, 1967). International Journal of Entomology Research. 2018; 3(4):20-21.

20. Cooper MI. Allometry for sexual dimorphism in millipedes (Diplopoda). Journal of Entomology and Zoology Studies. 2018a; 6(1):91-96.

21. Cooper MI. Sexual dimorphism in pill millipedes (Diplopoda). Journal of Entomology and Zoology Studies. 2018b; 6(1):613-616.

22. Cooper MI. Sexual size dimorphism and the rejection of Rensch's rule in Diplopoda (Arthropoda). Journal of Entomology and Zoology Studies. 2018c; 6(1):1582- 
1587.

23. Cooper MI, Telford SR. Copulatory Sequences and Sexual Struggles in Millipedes. Journal of Insect Behaviour. 13:217-230.

24. Dale J, Dunn PO, Figuerola J, Lislevand T, Székely T, Whittingham LA. Sexual selection explains Rensch's rule of allometry for sexual size dimorphism. Proceedings of the Royal Society B. 2007; 274:2971-2979.

25. David JF. Size criteria for the distinction between Cylindroiulus londinensis (Leach) and Cylindroiulus caeruleocinctus (Wood) (Diplopoda: Julidae). Journal of Natural History. 1995; 29:983-991.

26. Enghoff $\mathrm{H}$. The size of a millipede. In: Meyer E, Thaler $\mathrm{K}$, Schedl W (eds.) Advances in Myriapodology. Berichte des naturwissenschaftlich-medizinischen Vereins in Innsbruck, Supplement. 1992; 10:47-56.

27. Hopkin SP, Read HJ. The Biology of Millipedes. Oxford University Press, U. K., 1992, 246.

28. Leutenegger W. Scaling of sexual dimorphism in body size and breeding system in primates. Nature. 1978; 272:610-611.

29. Mori E, Mazza G, Lovari S. Sexual Dimorphism. In: Encyclopedia of Animal Cognition and Behavior ( $\mathrm{J}$. Vonk, and T. Shakelford, Eds). Springer International Publishing, Switzerland, 2017, 1-7.

30. Pincheira-Donoso D, Hunt J. Fecundity selection theory: concepts and evidence. Biological Reviews. 2015; 92:341-356.

31. Rowe M. Copulation, mating system and sexual dimorphism in an Australian millipede, Cladethosoma clarum. Australian Journal of Zoology. 2010; 58(2):127132.

32. Rensch B. Evolution above the Species Level. Columbia, New York, 1947, 419.

33. Rensch B. Die Abhängigkeit der relativen Sexualdifferenz von der Körpergrösse. Bonn Zoological Bulletin. 1950; 1:58-69.

34. Telford SR, Dangerfield JM. Sex in millipedes: laboratory studies on sexual selection. Journal of Biological Education. 1990; 24:233-238.

35. Telford SR, Dangerfield JM. Mating Tactics in the Tropical Millipede Alloporus uncinatus (Diplopoda: Spirostreptidae). Behaviour. 1993; 124:45-56.

36. Webb TJ, Freckleton RP. Only Half Right: Species with Female-Biased Sexual Size Dimorphism Consistently Break Rensch's Rule. PLoS ONE. 2007; 2(9):e897. 